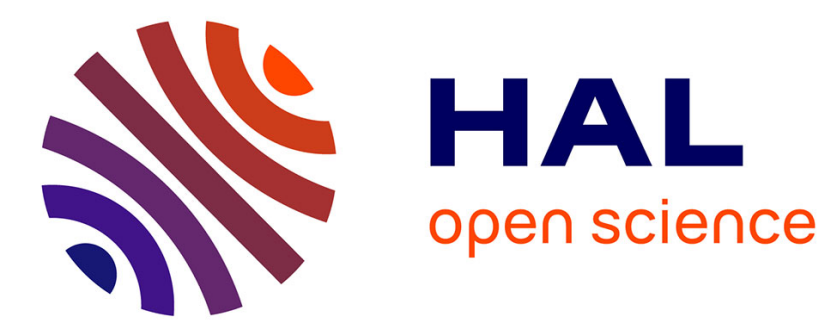

\title{
The effect of pyrolysis heating rate on the steam gasification reactivity of char from woodchips
}

Santiago Septien, Francisco Javier Escudero Sanz, Sylvain Salvador, Sylvie Valin

\section{- To cite this version:}

Santiago Septien, Francisco Javier Escudero Sanz, Sylvain Salvador, Sylvie Valin. The effect of pyrolysis heating rate on the steam gasification reactivity of char from woodchips. Energy, 2018, 142, pp.68-78. 10.1016/j.energy.2017.09.114 . hal-01639174

\section{HAL Id: hal-01639174 https://hal.science/hal-01639174}

Submitted on 23 Mar 2018

HAL is a multi-disciplinary open access archive for the deposit and dissemination of scientific research documents, whether they are published or not. The documents may come from teaching and research institutions in France or abroad, or from public or private research centers.
L'archive ouverte pluridisciplinaire HAL, est destinée au dépôt et à la diffusion de documents scientifiques de niveau recherche, publiés ou non, émanant des établissements d'enseignement et de recherche français ou étrangers, des laboratoires publics ou privés. 


\title{
The effect of pyrolysis heating rate on the steam gasification reactivity of char from woodchips
}

\author{
S. Septien ${ }^{\text {a, * }}$, F.J. Escudero Sanz ${ }^{\text {a }}$, S. Salvador ${ }^{\text {a }}$, S. Valin ${ }^{\text {b }}$ \\ a Mines - Albi, RAPSODEE, CNRS UMR 5302, Allée des sciences, 81000, Albi, France \\ ${ }^{\mathrm{b}}$ CEA, LITEN/DTBH/SBRT/LTCB, 38054, Grenoble cedex 9, France
}

Keywords:

Fluidized bed reactor

Woodchips

Char gasification

Heating rate

TGA

Modelling

\section{A B S T R A C T}

This work, performed in the context of Gaya project, focuses on the characterization and modelling of the effect of the pyrolysis heating rate on the steam gasification of char from woodchips. An experimental work was performed based on thermogravimetry and solid characterization of char samples prepared under different conditions. The results showed that gasification apparent reactivity increased with the increase of heating rate. The faster chemical kinetics of char prepared under high heating rate could be related to its higher catalytic inorganic content together with a more reactive carbonaceous structure. The increase of heating rate favours porosity development and the enlargement of pores, which would have a positive effect on gasification reaction rate by enhancing gas diffusion within the solid. The effect of heating rate on char gasification was included in a model previously developed, by correlating the chemical kinetics, particle density and diffusion rate to the char yield, which was selected as a suitable indicator of the heating rate. The new version of the model, considering the variability of heating rate during char formation, was validated through accurate predictions of the experimental results.

\section{Introduction}

Biomass gasification is a process with a high potential for energetic transition, as it represents a sustainable alternative to fossil fuels, with low greenhouse gas emission. Through this process, biomass is decomposed into a gas mixture, mainly composed of $\mathrm{H}_{2}$ and $\mathrm{CO}$, due to the action of heat and chemical reagents such as $\mathrm{H}_{2} \mathrm{O}, \mathrm{CO}_{2}$ or $\mathrm{O}_{2}$ in stoichiometric default. The gas produced through gasification has many energetic applications, such as the synthesis of biomethane that can be used as fuel for transportation and power generation.

The GAYA Project attempts to demonstrate the technical and economic feasibility of biomethane production through biomass gasification in France. The technology selected, a fast internally circulating fluidized bed (FICFB), couples a bubbling fluidized bed reactor for gasification and a transported bed reactor for combustion. In the gasifier, the biomass is pyrolyzed in an atmosphere composed of steam, resulting in the production of gas, tar and char. The pyrolysis products subsequently react among them and/or with the steam present in the atmosphere. Char is then partially gasified

\footnotetext{
* Corresponding author

E-mail address: santiago.septien@hotmail.com (S. Septien).
}

in the gasifier. In the combustor, the oxidation of the remaining char provides the required heat for the biomass gasification process, which is endothermic.

The char residence time in the gasifier, a key parameter of the process, needs to be optimised in order to simultaneously maximize the syngas production from char gasification, and leave enough residual solid for burning in the combustor to keep autothermicity. For this purpose, the understanding of char gasification process on the conditions of interest and the development of a predictive model is essential.

In a previous study [1], we showed that, under typical conditions of a fluidized bed reactor (FBR), the gasification rate of a woodchip char particle is controlled by chemical kinetics and internal transfer phenomena. Moreover, a semi-empirical kinetic model was developed to predict the gasification rate and was experimentally validated. This model is not able to provide a detailed description of char gasification, but it presents satisfactory levels of accuracy under the explored conditions. Physical models, such as the grain or volumetric model [2-4], are able to provide extensive information but their integration into a reactor model can be compromised by their complexity. Physical models have been simplified by capturing the main phenomena in a way as simple as possible $[5,6]$, but their level of complexity is still considerable. 


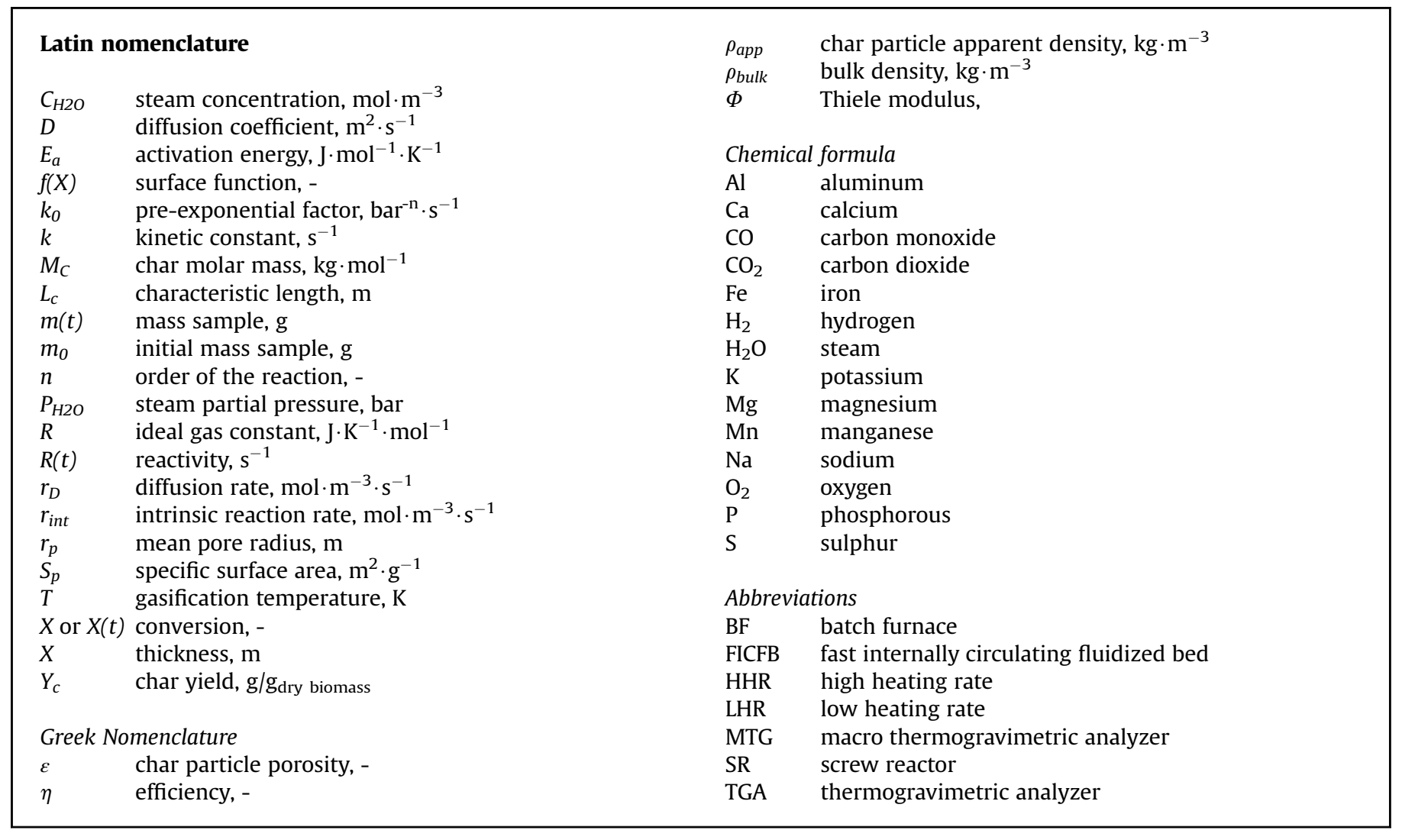

Compared to empirical modelling approaches based on the mathematical fitting of the results [7], the developed model owns a certain physical meaning.

The previous study was performed using char samples prepared under similar conditions, while it is known that char characteristics strongly depend on the conditions during its formation, in particular the heating rate. In a FBR, the heating rates are usually considered to be high with global heat transfer coefficients at particles surface in the range of $200-800 \mathrm{~W} \mathrm{~m}^{-2} \cdot \mathrm{K}^{-1}$ [8-10]. Nevertheless, because of the wideness of this range, the characteristics of a char from a FBR may vary.

The difference between a char prepared under low and high heating rate - respectively LHR and HHR char - has been studied in literature, through experiments in thermogravimetric analyzer (TGA), SEM observations, Raman spectroscopy analysis, measurements of density and porosity, and specific surface area determination. These investigations focus on coal as feedstock, as well as char from different types of biomass and different size ranges from millimeter to centimeter-size particles. In general, authors agree that fast pyrolysis leads to lower char formation and higher reactivity, in comparison to slow pyrolysis. Milosavljevic et al. [11] observed that the char yield from cellulose pyrolysis decreased by increasing the heating rate, which is in agreement with the results from lignin pyrolysis [12]. According to Robert et al. [13], the higher reactivity for a HHR char is due to its modifications of structure and surface area, rather than its effect of intrinsic reactivity. Similarly, Cetin et al. $[14,15]$ corroborated the higher reactivity of the HHR chars to a higher specific surface area. They also noted that, according to SEM observations, the LHR chars kept the initial biomass structure whereas the HHR char had a different morphology after being subjected to plastic deformations, in particular to swelling and melting during pyrolysis at atmospheric pressure. Biagini et al.
[16] studied the deformation of HHR chars produced at different temperatures. They concluded that at relatively low temperature (around $600{ }^{\circ} \mathrm{C}$ ), bubbling and swelling are the predominant phenomena leading to an enlargement of the particle, whereas at higher temperature $\left(800{ }^{\circ} \mathrm{C}\right)$ the particle slightly shrinks due to crack formation and melting of the material. Okumura et al. [17] analyzed the chemical structure of LHR and HHR chars by Raman spectroscopy, and they observed no crystalline structures in any of the samples. The lower reactivity of the LHR chars cannot then be explained by the presence of crystalline structures, which are usually low reactive. Instead of this, the authors related the higher reactivity of the HHR chars to the sparseness of its internal and external surface, which was the result of the high structural damage caused by the violent release of volatile compounds during fast pyrolysis. Guerrero et al. [18] linked the increase of reactivity at higher heating rate to the formation of more active sites for gasification reaction, which was experimentally reflected by a higher content of $\mathrm{O}$ and $\mathrm{H}$. A similar result was found in coal pyrolysis under a $\mathrm{CO}_{2}$ atmosphere, where the chars from fast pyrolysis were more oxygenated than those from slow pyrolysis [19]. However, the effect of heating rate in the elemental composition of char was not always noted, as for example in the case of lignin pyrolysis [12]. Mermoud et al. [20] showed that HHR chars are less dense and more porous than LHR chars, as also observed by Zanzi et al. [21]. Moreover, the pore size distribution is different between the samples: HHR chars tend to have a higher macroporosity but lower microporosity than LHR chars, which may. explain their higher reactivity. In fact, the authors assumed that mesoporous and macroporous surface are better indicator of reactivity than microporous surface, as micropores may not be active during gasification. The possible catalytic effect of inorganics on reactivity was also mentioned by Mermoud et al. [20], as ash content is higher in HHR 
chars due to a lower char yield. Besides, Kristiansen [22] proposed that low heating rates limit the dispersion of inorganics in char structure, which would consequently reduce their catalytic effect on reactivity. Zeng et al. [23] and Lu et al. [24] reported that the heating rate can have a negative effect on reactivity at high pyrolysis temperature (above $1200{ }^{\circ} \mathrm{C}$ ), as char structure ordering is favoured under these conditions.

The objective of the present work, performed in the context of GAYA project, is to characterize and model the effect of the pyrolysis heating rate on the steam gasification of char from woodchips. This study was carried out in large particles, where not enough studies have been done in literature, on the contrary to small particles. Indeed, most of the investigations focus on the effect of heating rate on the intrinsic characteristics and chemical kinetics, but almost none of them have investigated the effect on the bulk properties. A novel char gasification model considering the heating rate during pyrolysis was then developed.

This study was based on thermogravimetry experiments and solid characterization of char samples prepared under different pyrolysis conditions, over a wide range of particle size and of heating rate. The gasification model developed in the previous study [1], which is to be integrated into a fluidized bed reactor model [25], was modified in order to include the effect of pyrolysis heating rate. This inclusion will allow to apply the gasification model in different contexts (for example, fluidized bed reactor fed with char from slow pyrolysis).

\section{Materials and method}

\subsection{Woodchip characteristics}

Beech woodchips, one of the possible feedstock in GAYA project, were used in this study. The woodchips, provided from a French forestry cooperative, were issued from forests located in the middle of France. The woodchips were stored in closed room for several months before use.

The chemical composition of wood is given in Table 1 . The elemental analysis was provided by the woodchips supplier. The moisture content was measured by weighing the mass before and after oven drying at $105^{\circ} \mathrm{C}$, based on the French Standard NF-M-03002 . The ash content was measured by weighing the sample before and after calcination in an oven drying at $550{ }^{\circ} \mathrm{C}$, fallowing the standard CEN/TS 14775.

The size of the woodchips was very heterogeneous, with the width and length varying from several $\mathrm{mm}$ to a few $\mathrm{cm}$, and the thickness varying from $0.1 \mathrm{~mm}$ to $10 \mathrm{~mm}$.

\subsection{Char preparation}

Char samples were prepared from woodchips pyrolysis in high and low heating rate devices, under a nitrogen atmosphere.

Pyrolysis at high heating rate was performed in a macro TGA where the sample is rapidly introduced in the heated zone of the reactor and held there until the mass sample is stabilized - around $10 \mathrm{~min}$. This device is illustrated in Fig. 1 and the pyrolysis procedure is described with details in the previous work [1]. The

Table 1

Composition analysis of woodchips.

\begin{tabular}{lllllll}
\hline Moisture mass fraction (\%) & Ash dry mass fraction (\%) & \multicolumn{4}{l}{$\begin{array}{l}\text { Element dry ash-free } \\
\text { mass fraction (\%) }\end{array}$} \\
\cline { 2 - 6 } & & $\mathrm{C}$ & $\mathrm{H}$ & $\mathrm{O}$ & $\mathrm{N}$ \\
\hline 8 & 0.6 & 49.4 & 5.7 & 44.5 & 0.3 \\
\hline
\end{tabular}

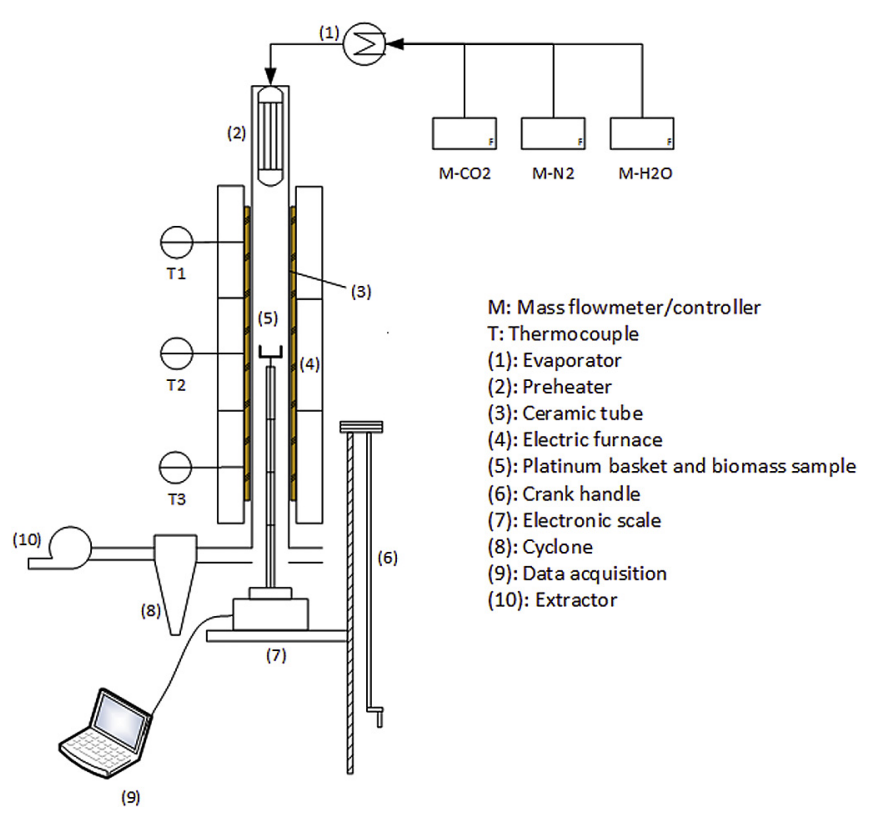

Fig. 1. Scheme of the macro TGA facility.

heating rate is estimated to be in the order of $100{ }^{\circ} \mathrm{C} / \mathrm{s}$ [26]. In order to lead to different heating rates, the reactor was set at different pyrolysis temperatures: $650,750,850$ and $950{ }^{\circ} \mathrm{C}$.

Pyrolysis at low heating rates was performed using a continuous screw reactor and a conventional batch furnace:

- In the screw reactor (SR), woodchips were slowly introduced into the reactor set at $750{ }^{\circ} \mathrm{C}$, leading to low heating rates estimated in the order of $1^{\circ} \mathrm{C} / \mathrm{s}$ [27], and kept there during $1 \mathrm{~h}$.

- In the batch furnace (BF), the sample was heated at the same time as the device, at a temperature ramp of approximately $0.05^{\circ} \mathrm{C} / \mathrm{s}$ until reaching $900{ }^{\circ} \mathrm{C}$.

Prior to the pyrolysis in the macro TGA and the batch furnace, woodchips with a regular parallelepiped shape were selected and sorted according to their thickness. In fact, Van de Steene [28] experimentally demonstrated that thickness is a representative dimension with respect to apparent kinetics for char from woodchips. In the case of the screw reactor, sorting was performed on the char samples. Indeed, the screw reactor operates at high feeding rates of several $\mathrm{kg} / \mathrm{h}$, on the contrary to macro TGA and batch reactor which admit small loads of sample of a few $\mathrm{g}$. Therefore, a selection before pyrolysis in the screw reactor was not a feasible option.

Additionally, a char sample was prepared from the pyrolysis of sawdust in a drop tube reactor (DTR) set at $800^{\circ} \mathrm{C}$, under a nitrogen carrier flow of $18.8 \mathrm{NL} \cdot \mathrm{min}^{-1}$. The sawdust was from the same wood species as the woodchips. The residence time of the particles in the DTR was of approximately about $5 \mathrm{~s}$. The heating rate in this device is estimated at $1000 \mathrm{C} / \mathrm{s}$. The description of the sawdust, the DTR and the pyrolysis experimental procedure is provided by Septien et al. [29]. The sawdust particle size was $0.31-0.40 \mathrm{~mm}$. This range was obtained after sieving, based on the width of the particle. The particle size of char from sawdust was $0.22-0.28 \mathrm{~mm}$, after applying a shrinking factor estimated at 0.75 [30].

Table 2 summarizes the nomenclature, particle size, conditions of preparation and char yield of the samples used in this work. The char yield was calculated as the ratio of the sample mass weighed after pyrolysis to its mass weighed before pyrolysis for the MTG and 
Table 2

Characteristics of char samples.

\begin{tabular}{|c|c|c|c|c|c|c|c|}
\hline \multirow[t]{2}{*}{ Sample name } & \multirow[t]{2}{*}{ Wood thickness (mm) } & \multicolumn{2}{|c|}{ Char thickness (mm) } & \multicolumn{3}{|c|}{ Conditions of preparation } & \multirow[t]{2}{*}{ Char yield (w\%, dry } \\
\hline & & Range & Mean value & Furnace & $\mathrm{T}\left({ }^{\circ} \mathrm{C}\right)$ & $\operatorname{HR}\left({ }^{\circ} \mathrm{C} / \mathrm{s}\right)$ & \\
\hline DTR & N.A. & N.A. & N.A. & DTR & 800 & $\sim 1000$ & $5.0 \pm 1.0$ \\
\hline $\mathrm{MTG} 950^{\circ} \mathrm{C}-1.8 \mathrm{~mm}$ & $2.5-3.5$ & $1.5-2.1$ & 1.8 & Macro TGA & 950 & $\sim 100$ & $12.5 \pm 0.2$ \\
\hline $\mathrm{MTG} 850^{\circ} \mathrm{C}-0.6 \mathrm{~mm}$ & $0.5-1.5$ & $0.3-0.9$ & 0.7 & Macro TGA & 850 & $\sim 100$ & $11.9 \pm 1.4$ \\
\hline MTG850 ${ }^{\circ} \mathrm{C}-1.2 \mathrm{~mm}$ & $1.5-2.5$ & $0.9-1.5$ & 1.3 & Macro TGA & 850 & $\sim 100$ & $12.7 \pm 1.5$ \\
\hline $\mathrm{MTG} 850^{\circ} \mathrm{C}-1.8 \mathrm{~mm}$ & $2.5-3.5$ & $1.5-2.1$ & 1.8 & Macro TGA & 850 & $\sim 100$ & $13.4 \pm 0.3$ \\
\hline $\mathrm{MTG} 850^{\circ} \mathrm{C}-2.4 \mathrm{~mm}$ & $3.5-4.5$ & $2.1-2.7$ & 2.3 & Macro TGA & 850 & $\sim 100$ & $13.8 \pm 0.4$ \\
\hline MTG850 ${ }^{\circ} \mathrm{C}-3.0 \mathrm{~mm}$ & $4.5-5.5$ & $2.7-3.3$ & 2.8 & Macro TGA & 850 & $\sim 100$ & $14.1 \pm 0.2$ \\
\hline $\mathrm{MTG}^{2} 50^{\circ} \mathrm{C}-1.8 \mathrm{~mm}$ & $2.5-3.5$ & $1.5-2.1$ & 1.7 & Macro TGA & 750 & $\sim 100$ & $14.4 \pm 0.9$ \\
\hline $\mathrm{MTG} 650^{\circ} \mathrm{C}-1.8 \mathrm{~mm}$ & $2.5-3.5$ & $1.5-2.1$ & 1.7 & Macro TGA & 650 & $\sim 100$ & $16.3 \pm 0.9$ \\
\hline SR-0.6 mm & N.A. & $0.3-1.2$ & 1.0 & Screw reactor & Up to 750 & $\sim 1$ & $20.0 \pm 1.9$ \\
\hline $\mathrm{SR}-1.2 \mathrm{~mm}$ & N.A. & $1.2-1.6$ & 1.4 & Screw reactor & Up to 750 & $\sim 1$ & $20.0 \pm 1.9$ \\
\hline $\mathrm{SR}-1.8 \mathrm{~mm}$ & N.A. & $1.6-2.0$ & 1.7 & Screw reactor & Up to 750 & $\sim 1$ & $20.0 \pm 1.9$ \\
\hline SR-2.4 mm & N.A. & $2.0-2.6$ & 2.3 & Screw reactor & Up to 750 & $\sim 1$ & $20.0 \pm 1.9$ \\
\hline SR-3.0 mm & N.A. & $2.6-3.0$ & 2.9 & Screw reactor & Up to 750 & $\sim 1$ & $20.0 \pm 1.9$ \\
\hline LHR-BF-1.8 mm & $2.5-3.5$ & $1.7-2.3$ & 2.0 & Batch reactor & Up to 900 & $\sim 0.05$ & $22.6 \pm 3.0$ \\
\hline
\end{tabular}

BF chars. Due to some technical constraints, this method was not possible to apply for the DTR and SR chars. The ash tracer method was consequently used for these samples [29]. This method was validated by applying it to the MTG $850^{\circ} \mathrm{C}-1.8 \mathrm{~mm}$ sample: a similar char yield was found between the ash tracer and weighing method $(14.7 \pm 1.6 \mathrm{w} \%$ for the tracer method versus $13.4 \pm 0.3 \mathrm{w} \%$ for the weighing method).

Note that an average value was selected for the char yield of the SR samples, as this was practically the same regardless the particle size.

\subsection{Leaching of char samples by water washing}

Char leaching was performed for the MTG850 ${ }^{\circ} \mathrm{C}-1.8 \mathrm{~mm}$ and SR$1.8 \mathrm{~mm}$ samples, which were previously ground and sieved to a particle size inferior to $0.250 \mathrm{~mm}$. The aim was to remove inorganic elements from the char, in particular potassium which is known as one of the most influencing element on char reactivity due to its high catalytic effect $[31,32]$.

The experimental procedure was based on the study of Jensen et al. [33] focusing on the extraction of potassium and chloride by water washing. Each of the samples was introduced into a batch stirred reactor containing $100 \mathrm{ml}$ of demineralized water. The reactor was heated to $80^{\circ} \mathrm{C}$ as the inorganics extraction best occurs at high temperature. This procedure was launched for several days until mineral composition of washing water, measured by ICP, remained constant. Then, the solid was recovered after Buchner filtration and dried at $105{ }^{\circ} \mathrm{C}$ into an oven during a couple of days. The inorganic composition of the leached char was measured by ICP, after calcination at $550{ }^{\circ} \mathrm{C}$ and ash mineralization with aqua regia and a solution of $\mathrm{HF} / \mathrm{HClO}_{4}$. The inorganic content of the MTG $850^{\circ} \mathrm{C}-1.8 \mathrm{~mm}$ and SR-1.8 $\mathrm{mm}$ samples, before and after leaching, is displayed in Table 3.

Note that the content of sodium, iron, sulphur and aluminum for the MTG850 ${ }^{\circ} \mathrm{C}-1.8 \mathrm{~mm}$ sample was higher after leaching, which was probably due to their low concentration leading to a high experimental uncertainty. The contents of calcium, potassium and magnesium were relatively high, so they were the most reliable measurements.

\subsection{Gasification experiments in the macro TGA}

Gasification experiments were performed in the macro TGA, in a mixture of steam and $\mathrm{N}_{2}$. The temperature was varied between 750 and $950{ }^{\circ} \mathrm{C}$, and the steam concentration between 15 and $50 \mathrm{~mol} \%$, while the gas velocity in the reactor was kept constant at $0.2 \mathrm{~m} \mathrm{~s}^{-1}$ by varying the flowrate in the range $11.8-14.2 \mathrm{Nl} \cdot \mathrm{min}^{-1}$. The carrier gas velocity did not exhibit any influence in char gasification rate in previous experiments [1]. Char samples were used in their raw form to determine apparent kinetics, or were previously ground and sieved to a particle size inferior to $0.250 \mathrm{~mm}$ to determine the intrinsic reactivity, i.e. reactivity in a kinetically controlled regime. A few experiments were conducted with the leached char samples so as to determine the intrinsic kinetics by limiting the inorganics influence on gasification (refer to section 2.3).

The introduction of the sample into the reactor was performed in a $\mathrm{N}_{2}$ gas stream. Only after the stabilization of the sample mass, the atmosphere was changed to a wet one. The gasification experimental procedure is described with details by Septien et al. [1].

From the mass loss measured during the macro TGA experiments, the conversion $X(t)$ and reactivity $R(t)$ were calculated with equations (1) and (2) respectively. The average value of the reactivities in the conversion range of $20-80 \%$, calculated by numerical integration of the experimental data, was selected for the data analysis. Each experiment was repeated from 2 to 5 times. The uncertainty bar of the reactivity was calculated from the replicates, by applying a t-Student distribution in a $90 \%$ confidence interval.

Table 3

Mineral content of char samples before and after leaching.

\begin{tabular}{|c|c|c|c|c|c|c|c|c|c|c|c|c|c|}
\hline \multirow[t]{2}{*}{ Sample } & & \multirow[t]{2}{*}{ Dry ash mass fraction (\%) } & \multicolumn{11}{|c|}{ Concentration in char $(\mathrm{g} / \mathrm{kg})$} \\
\hline & & & $\mathrm{Al}$ & $\mathrm{Ca}$ & $\mathrm{Fe}$ & K & $\mathrm{Mg}$ & $\mathrm{Mn}$ & $\mathrm{Na}$ & $\mathrm{P}$ & $S$ & $\mathrm{Si}$ & $\mathrm{Ti}$ \\
\hline \multirow[t]{2}{*}{$\mathrm{MTG} 850^{\circ} \mathrm{C}-1.8 \mathrm{~mm}$} & Before leaching & 4.0 & 0.3 & 7.3 & 0.9 & 6.5 & 2.4 & 0.4 & 0.1 & 0.9 & 0.2 & 0.5 & 0.1 \\
\hline & After leaching & 2.4 & 0.4 & 6.2 & 1.7 & 0.3 & 1.7 & 0.0 & 0.5 & 0.1 & 0.3 & 0.0 & 0.1 \\
\hline \multirow[t]{2}{*}{ SR-1.8 mm } & Before leaching & 2.9 & 0.2 & 5.4 & 0.7 & 4.7 & 1.8 & 0.3 & 0.1 & 0.7 & 0.3 & 0.3 & 0.0 \\
\hline & After leaching & 1.4 & 0.1 & 0.8 & 0.6 & 0.1 & 0.4 & 0.1 & 0.1 & 0.2 & 0.1 & 0.1 & 0.0 \\
\hline
\end{tabular}


$X=\frac{m_{0}-m(t)}{m_{0}}$

$R(t)=-\frac{1}{m(t)} \cdot \frac{d m}{d t}$

\subsection{Characterization of char samples}

The char samples morphology was characterized before gasification, with the measurement of the bulk density, apparent density and specific surface area.

The bulk density of ground char samples was measured using a pycnometer Micromeritic AccuPyc 1330. The apparent density of raw char particles was calculated by weighing and measuring the particle dimensions to deduce the volume. The specific surface area of ground char samples was measured using a BET analyzer Micromeritics Tristart II.

From the bulk density $\rho_{\text {bulk }}$ and the apparent density $\rho_{\text {app }}$, char porosity $\varepsilon$ was calculated with equation (3). The mean pore radius $r_{p}$ could be estimated from the porosity, specific surface area $S_{p}$ and apparent density, using equation (4). For technical reasons, the pore size distribution could not be obtained in the BET analyzer.

$\varepsilon=1-\frac{\rho_{a p p}}{\rho_{\text {bulk }}}$

$r_{p}=\frac{4 \cdot \varepsilon}{S_{p} \cdot \rho_{a p p}}$

A t-Student distribution was applied to calculate the uncertainty bar in a confidence interval of $90 \%$ from the replicates. The bulk density measurements were repeated 2 to 3 times. The apparent density was measured for at least 15 particles for each sample. The uncertainty bar of porosity was calculated by the uncertainty propagation from the apparent and bulk densities. The specific surface area measurement could only be performed once due to practical reasons. Therefore, the values of specific surface area and mean pore radius are rough estimations.

Observations in a scanning electronic microscope (SEM), model Philips XL 30 ESEM FEG, were performed for the MTG850 ${ }^{\circ} \mathrm{C}-1.8 \mathrm{~mm}$, SR-1.8 mm and BF-1.8 mm chars. As chars are usually non-electrical conductive materials, the samples were coated by a thin gold layer in order to enable the imaging. Several longitudinal, radial and cross-sectional views were done in the samples during the SEM observations. The most representative images were recorded as photographs.

\section{Char gasification model}

The gasification model developed in a previous was extended for char samples prepared under different heating rates. This section gives a brief description of the model and the modifications performed in order to include the effect of the heating rate.

\subsection{Description of the previous model}

Based on the requirements of simplicity and reliability set in GAYA project, a semi-empirical model was developed in order to predict char gasification rate in a fluidized bed reactor. The effectiveness modelling approach was adopted for this, assuming that the external transfers are not rate limiting and that the particle is isothermal. The model globally predicts with accuracy the gasification rate in the conditions of interest.

In the modelling approach adopted, the reaction rate is written as a function of the effectiveness factor $\eta$, the intrinsic reaction rate $r_{i n t}$ and the surface function $f(X)$, as seen in equation (5).

$r_{\text {app }}=\eta \cdot r_{\text {int }} \cdot f(X)$

The effectiveness factor represents the reaction rate decrease due to transfer limitations, compared to the intrinsic reaction rate. For isothermal particles of any geometry, the effectiveness factor of a reaction rate controlled by chemical kinetics and porous diffusion can be written as a function of Thiele modulus $\Phi$, as shown in equation (6). Thiele modulus is a dimensionless number defined as the ratio between the reaction rate if controlled only by chemical kinetics and that if only controlled by diffusion rate. It can be expressed by equation (7) in its normalized form, for $n$th order reactions.

$\eta=\frac{\tanh (\varnothing)}{\varnothing}$

$\varnothing=\sqrt{\left(\frac{1+n}{2}\right) \cdot \frac{r_{i n t}}{r_{D}}}$

The use of equation (6) in the model implies that char particle size has to be represented by its characteristic length $L_{C}$, here defined as the ratio between the volume and the surface of the particle. After measuring the dimensions of several particles of different sizes, an empirical expression of characteristic length (8), as a function of char thickness $x$, was established by mathematical fitting of the experimental data.

$L_{c}=x / 3$

The intrinsic reaction rate $r_{i n t}$ is related to the chemical kinetic constant $k$, the molecular weight $M_{C}$ and the density $\rho_{a p p}$ of char through equation (9). The chemical kinetic constant, detailed in equation (10), was determined from thermogravimetry experiments in intrinsic conditions, which are described with detail in Ref. [1]. As chars are usually mainly composed of carbon, the molecular weight $M_{C}$ is supposed to be near to that of carbon, i.e. $0.012 \mathrm{~kg} \mathrm{~mol}^{-1}$. The density of char was set at $225 \mathrm{~kg} \mathrm{~m}^{-3}$, which is the average value from samples of different sizes, prepared in the macro TGA at $850^{\circ} \mathrm{C}$.

$r_{\text {int }}=\frac{k \cdot \rho_{a p p}}{M_{C}}$

$k=7.349 \cdot 10^{7} \cdot \exp (-274000 / R \cdot T) \cdot P_{H 2 O}^{0.65}$

The diffusion rate of steam within the char particle $r_{D}$ is derived from Fick's law, according to equation (11). The steam concentration $C_{H 2 O}$ is expressed as a function of temperature $T$ and steam partial pressure $P_{\mathrm{H} 2 \mathrm{O}}$ through the perfect gas law, as seen in equation (12). In this model, the diffusion coefficient $D$ was expressed by equation (13), an empirical expression obtained from mathematical fitting. The order of magnitude of the diffusion coefficient $\left(10^{-6} \mathrm{~m}^{2} \mathrm{~s}^{-1}\right)$ was lower to the theoretically expected $\left(10^{-5} \mathrm{~m}^{2} \mathrm{~s}^{-1}\right)$, leading to the hypothesis that other rate limiting phenomena are lumped in the diffusion coefficient, as for instance the gasification inhibition by the products $\mathrm{CO}$ and $\mathrm{H}_{2}$ while diffusing out of the particle [1]. 
$r_{D}=\frac{D}{L_{C}^{2}} \cdot C_{H 2 O}$

$$
C_{H 2 O}=\frac{P_{H 2 O}}{R \cdot T}
$$

$D=2.53 \cdot 10^{11} \cdot T^{-3.8}$

The surface function $f(X)$ implicitly describes the evolution of the char reactive surface during the transformation. In the case of char from biomass, the reactive surface evolution is reported to be very complex as it involves modification in both the carbonaceous and inorganic matrix as the reactions proceeds. In order to remain with a simple model, an empirical surface function in the form of a 6 th degree polynomial, observed in equation (14), was selected to represent the surface function, as frequently done in literature.

$$
\begin{aligned}
f(X)= & 26.92 X^{6}-48.33 X^{5}+26.06 X^{4}+4.15 X^{3} \\
& -5.67 X^{2}+1.95 X+0.34
\end{aligned}
$$

\subsection{Modification of the model}

The gasification model described in previous section was modified in order to include the effect of the heating rate during char formation in an empirical way.

For this, the parameters identified as the more sensitive to the heating rate, i.e. chemical kinetic constant, char density and diffusion coefficient, were correlated to the char yield $Y_{c}$ that was selected as a suitable indicator of the heating rate. In fact, it is widely accepted that char yield depends on the heating rate: it always decreases as the heating rate increases. Beside, char yield is an easily measurable parameter, unlike the heating rate.

The new expressions of the kinetic constant, the char apparent density and the diffusion coefficient, obtained from mathematical fitting of the experimental data with respect to the char yield, are shown in equations (15)-(17) respectively. Equation (15) was obtained from the intrinsic reactivities measured in the macro TGA for the ground $1.8 \mathrm{~mm}$ samples, at $780^{\circ} \mathrm{C}$ and with $15 \%$ mole fraction of steam. This expression implies that only the pre-exponential factor is affected by the heating rate during pyrolysis, while the activation energy and order of the reaction remain the same. As commented by Di Blasi [34], there is no specific trend of the effect of the heating rate on the activation energy and the order of the reaction in literature. Equation (16) was obtained from the apparent densities measured for the $1.8 \mathrm{~mm}$ samples (refer to section 2.5). Equation (17) was obtained from the diffusion coefficients determined by fitting the model predictions to the results from the gasification experiments at $850^{\circ} \mathrm{C}$ and under $35 \%$ mole fraction of steam, with the $1.8 \mathrm{~mm}$ samples.

$k=1.01 \cdot 10^{10} \cdot Y_{C}^{-1.3} \cdot \exp (-274000 / R \cdot T) \cdot P_{H 2 O}^{0.54}$

$\rho_{C}=1680 \cdot Y_{C}$

$D=13900 \cdot Y_{C}^{-0.5} \cdot T^{-3.8}$

Note that the expressions of the surface function and the characteristic length are valid for the different char samples, as demonstrated in Figs. 2 and 3, and then do not depend on the pyrolysis heating rate.

\section{Results and discussion}

\subsection{Effect of the heating rate}

Fig. 4 compares the reactivity of char samples prepared under low and high heating rates, during gasification experiments at $850{ }^{\circ} \mathrm{C}$ with $35 \%$ mole fraction of steam. It can be seen that globally the reactivity of the MTG-1.8 $\mathrm{mm}$ chars is higher than that of the SR-1.8 mm and BF-1.8 mm chars. Among the HHR samples, the reactivity increases with the pyrolysis temperature. Among the LHR samples, no significant difference could be observed due to the high uncertainty bar of the BF-1.8 mm sample.

The results clearly show that reactivity increases with heating rate. The difference of reactivity between the HHR and LHR chars is important. Among the HHR chars, the pyrolysis temperature (so the heating rate) has a slight effect.

Possible explanations about the difference of reactivity between the HHR and LHR chars are discussed in the next sections, focusing on the intrinsic kinetics and physical properties of char samples.

\subsubsection{Effect of heating rate on the char yield}

The heating rate during pyrolysis largely affects the char yield, which tends to decrease as the heating rate increases. Different factors affect the heating rate, such as the applied pyrolysis technology, the operating conditions and the characteristics of the sample (size and geometry). Pyrolysis temperature is another relevant factor by its direct impact on char formation and its influence on the heating rate. For example, at higher temperatures, the heating rate is higher and char formation is disadvantaged.

The negative effect of the heating rate in char yield can be observed in Table 2. The DTR and MTG samples, prepared at high heating rate, have a lower char yield than the samples prepared at low heating rate, the SR and BF samples. The effect of pyrolysis temperature could be seen on the MTG samples, for which the char yield decreases as the pyrolysis temperature increases. In the case of SR and BF samples, pyrolysis temperature does not have any effect, as the char yields are always lower than the MTG samples, in despite of a higher temperature in some of the cases. For example, the SR sample had a lower char yield compared to the MTG650 sample (char yield of $20 \%$ wt versus $16.3 \%$ ), in despite of higher pyrolysis temperature $\left(750^{\circ} \mathrm{C}\right.$ versus $\left.650^{\circ} \mathrm{C}\right)$. A similar observation happens to the BF sample (char yield of $22.6 \% \mathrm{wt}$ at $900{ }^{\circ} \mathrm{C}$ ). It has to be also considered that the SR and BF samples were probably pyrolyzed before reaching the furnace set temperature, due to the low heating rates.

Char yield depends on particle size for the MTG samples, whereas this is not the case for the SR samples. As a plausible explanation, the low heating rates in the screw reactor allow a progressive and homogeneous heating of the sample regardless its size, making any difference on the char yield under the explored particle size range. On the contrary, under high heating rates, the surface of the solid is rapidly heated and creates a temperature difference with respect to the interior of the particle. This behavior should be emphasized as the particle size increases. Heat transfer inside larger particles takes longer time to occur compared to smaller particles, leading to a lower heating rate and therefore to a lower char yield, as seen for the MTG samples (Table 2).

In the case of the DTR sample (sawdust), the fine particle size leads to very high heating rates, leading to a considerably lower char yield than the rest of the samples (woodchips).

\subsubsection{Effect of heating rate on the intrinsic reactivity}

Fig. 5 a displays the reactivities measured during the gasification of ground HHR and LHR char samples at $780{ }^{\circ} \mathrm{C}$ and with $35 \%$ mole fraction of steam. Under these conditions, the gasification was 


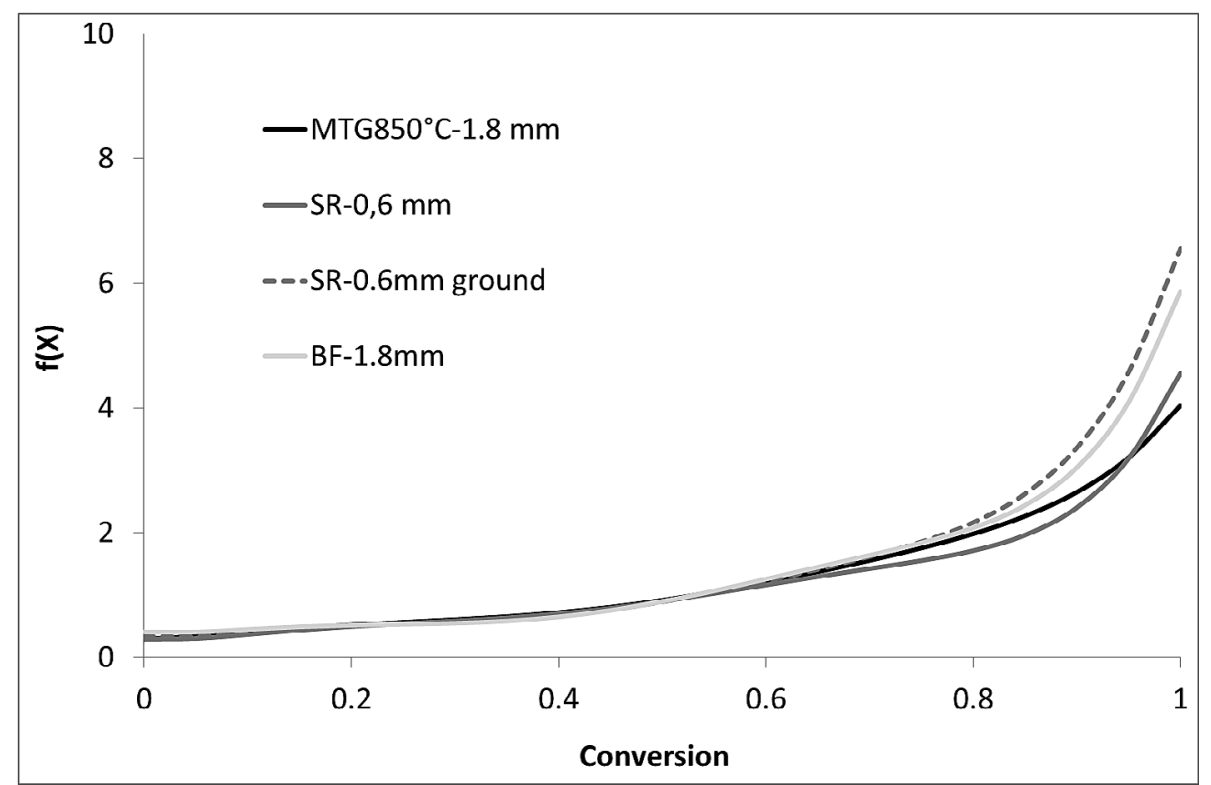

Fig. 2. Surface function for different char samples.

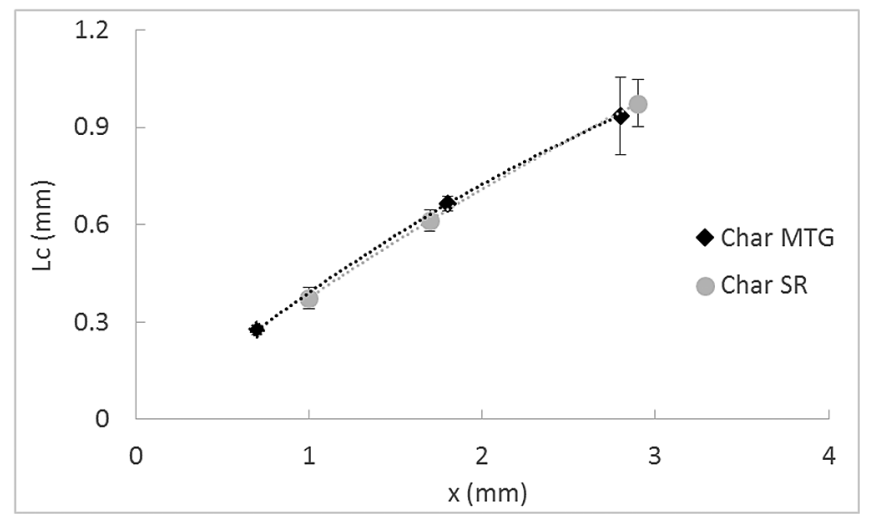

Fig. 3. Characteristic length versus particle thickness for the MTG850 ${ }^{\circ} \mathrm{C}-1.8 \mathrm{~mm}$ and SR-1.8 mm samples.

verified to occur in a kinetically controlled regime [1].

As it could be expected according to the literature [13-15], the intrinsic reactivity increases with heating rate: the DTR sample exhibits the highest reactivity, followed by MTG850 ${ }^{\circ} \mathrm{C}-1.8 \mathrm{~mm}$, SR$1.8 \mathrm{~mm}$ and BF-1.8 mm chars in a reactivity decreaings order. A possible explanation for this trend is the different ash content between the char samples. Indeed, the increase of the heating rate leads to a lower char yield (refer to section 4.1.1) and consequently to a higher ash content, assuming that inorganics remain in the solid during pyrolysis. As an illustration of this, the MTG850 ${ }^{\circ} \mathrm{C}$ $1.8 \mathrm{~mm}$ and SR-1.8 $\mathrm{mm}$ samples have an ash content of 4 and $3 \%$ mass fraction respectively. It is well known that the alkali and alkaline earth metals are catalyst of gasification reaction, in particular potassium and calcium. The ash of the samples is composed of around 20 and $30 \%$ of mass fraction of potassium and calcium respectively, so it likely has a catalytic effect on gasification.

In order to investigate the catalytic effect of ash, the intrinsic reactivities of the MTG $850^{\circ} \mathrm{C}-1.8 \mathrm{~mm}$ and SR-1.8 $\mathrm{mm}$ samples, before and after leaching, are compared in Fig. 5b. Table 4 presents the inorganics removal performance after char leaching, measured by two different methods: one method compares the char ash composition before and after leaching, while the other uses the washing water composition. The compounds other than magnesium, calcium and potassium are excluded from this analysis,

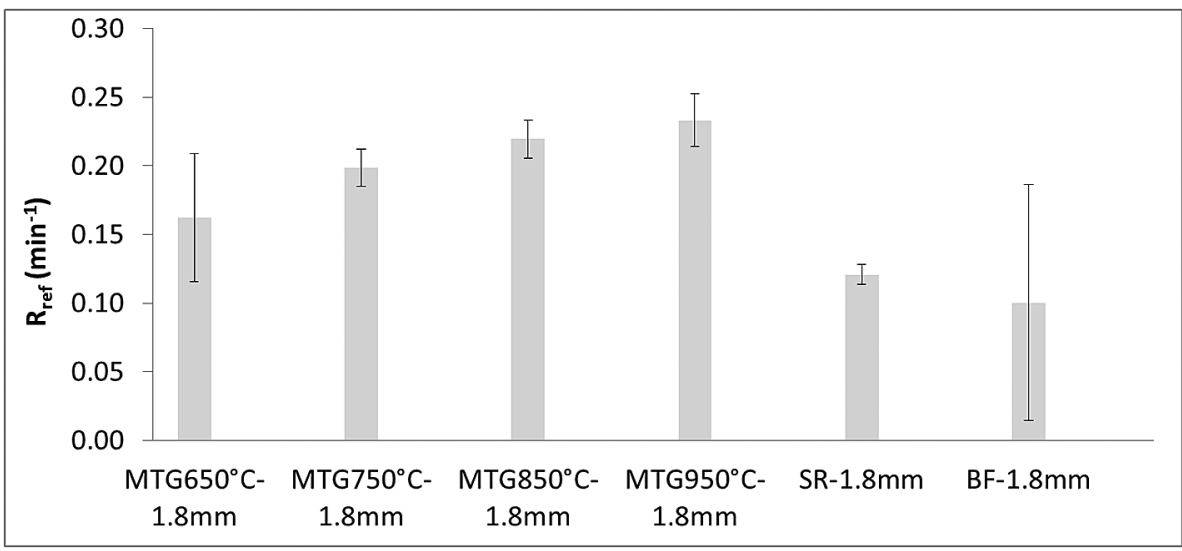

Fig. 4. Reactivity measured during the gasification of char samples at $850{ }^{\circ} \mathrm{C}$, with $35 \%$ mole fraction of steam. 

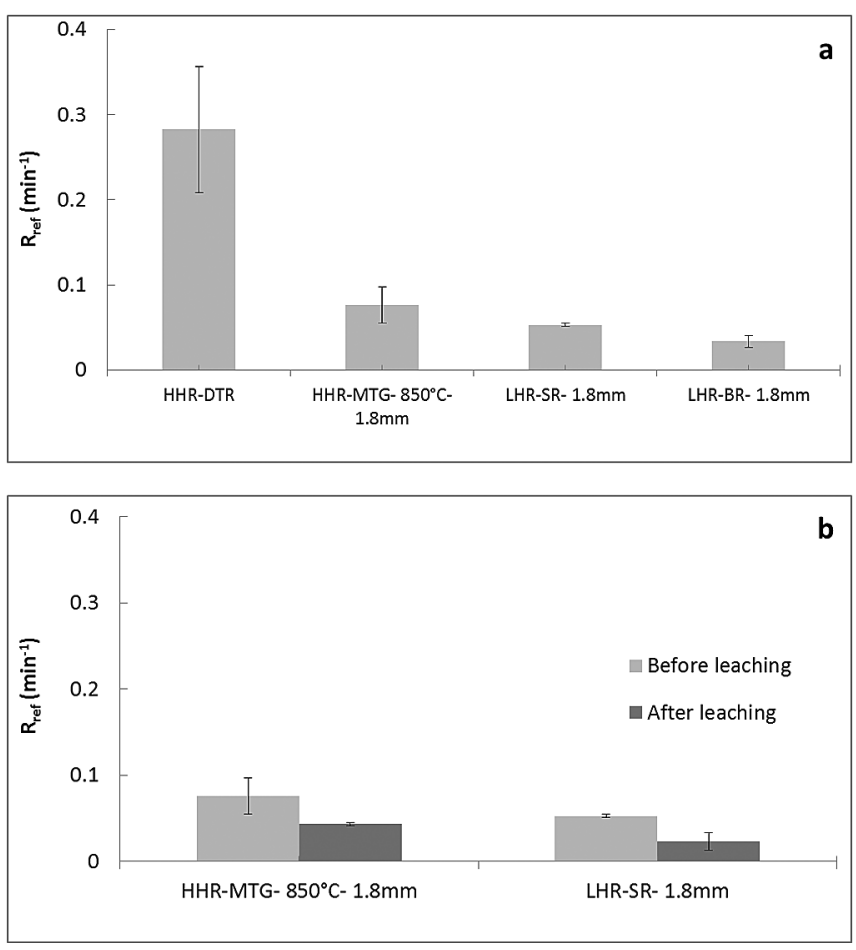

Fig. 5. Intrinsic reactivity measured during the gasification of ground char samples at $780{ }^{\circ} \mathrm{C}$, with $15 \%$ mole fraction of steam (a); intrinsic reactivities of ground char before and after leaching (b).

because of the high uncertainty of their removal related to their low concentrations. Despite of the disagreements between the two methods, it can be concluded that the results obtained after char leaching were quite positive for both char samples: the total inorganic content is reduced to approximately the half, the samples are mostly depleted of potassium, and magnesium and calcium are partly removed.

According to Fig. 5b, the reactivity of the leached chars is about half that of the non-leached char, for both for MTG and SR chars. This result highlights the catalytic effect of inorganics on gasification. Moreover, the difference of reactivity between the MTG $850^{\circ} \mathrm{C}$ $1.8 \mathrm{~mm}$ and SR-1.8 mm leached chars, is kept as large as that between the samples before leaching. This result suggests that the ash catalytic effect cannot completely explain the difference of reactivity between a HHR and a LHR char. The carbonaceous matrix should be then by itself more reactive in the case of the HHR char.

\subsubsection{Effect of the heating rate on the physical properties}

Table 5 presents the physical characteristics of the char samples. The bulk density is similar for most of the samples, around $1700 \mathrm{~kg} \mathrm{~m}^{-3}$. The exceptions are the BF- $1.8 \mathrm{~mm}$ and the MTG650C$1.8 \mathrm{~mm}$ samples with values around 1900 and $1500 \mathrm{~kg} \mathrm{~m}^{-3}$ respectively. The apparent density globally decreases by increasing the heating rate. The porosity varies in the interval $80-90 \%$ with an
Table 5

Morphological characteristics of char samples.

\begin{tabular}{llllll}
\hline Sample & $\rho_{\text {bulk }}\left(\mathrm{kg} / \mathrm{m}^{3}\right)$ & $\rho_{\text {app }}\left(\mathrm{kg} / \mathrm{m}^{3}\right)$ & $\varepsilon(\%)$ & $\mathrm{S}_{\mathrm{p}}\left(\mathrm{m}^{2} / \mathrm{g}\right)$ & $\mathrm{r}_{\mathrm{p}}(\mathrm{nm})$ \\
\hline MTG950 $^{\circ} \mathrm{C}-1.8 \mathrm{~mm}$ & $1759 \pm 36$ & $176 \pm 12$ & $90 \pm 6$ & $\sim 3$ & $\sim 5000$ \\
MTG850 $^{\circ} \mathrm{C}-1.8 \mathrm{~mm}$ & $1713 \pm 128$ & $219 \pm 10$ & $87 \pm 8$ & $\sim 150$ & $\sim 100$ \\
MTG750 $^{\circ} \mathrm{C}-1.8 \mathrm{~mm}$ & $1660 \pm 70$ & $238 \pm 20$ & $86 \pm 8$ & $\sim 250$ & $\sim 60$ \\
MTG650 $^{\circ} \mathrm{C}-1.8 \mathrm{~mm}$ & $1521 \pm 78$ & $240 \pm 16$ & $84 \pm 7$ & $\sim 340$ & $\sim 40$ \\
$\mathrm{SR}-1.8 \mathrm{~mm}$ & $1685 \pm 22$ & $308 \pm 9$ & $82 \pm 3$ & $\sim 190$ & $\sim 60$ \\
$\mathrm{BF}-1.8 \mathrm{~mm}$ & $1884 \pm 29$ & $357 \pm 28$ & $81 \pm 6$ & $\sim 370$ & $\sim 20$ \\
\hline
\end{tabular}

apparent increase as the heating rate increases. However, the uncertainty associated with porosity is too high to allow this trend to be confirmed.

Globally, the specific surface tends to decrease and the mean char radius size to increase as the pyrolysis occurs at higher heating rate. Among the MTG samples, the same trend can be observed as the pyrolysis temperature increases. The MTG samples have a lower specific surface area and a higher mean radius pore than the BF$1.8 \mathrm{~mm}$ sample. The exception of this trend is the SR sample which has similar specific surface and mean pore radius than the MTG750 ${ }^{\circ} \mathrm{C}-1.8 \mathrm{~mm}$ samples.

Note that the specific surface is rather an indicator of the microporosity surface than that of the total porosity, as explained by Mermoud et al. [20]. Therefore, the relative low specific surface exhibited by the MTG $950^{\circ} \mathrm{C}-1.8 \mathrm{~mm}$ reflects a large pores structure, whereas the high specific surface from the BF- $1.8 \mathrm{~mm}$ should imply a structure with smaller pores. This reinforces the hypothesis of pore size enlargement by increasing the heating rate.

Fig. 6 displays SEM photographs of the MTG850 ${ }^{\circ} \mathrm{C}-1.8 \mathrm{~mm}$, SR$1.8 \mathrm{~mm}$ and BF-1.8 mm samples. It can be noted that the samples keep the wood fibrous structure (Fig. 6a, e and h), regardless the pyrolysis heating rate. The cross-section view of char particles shows that the capillaries from the wood are still present for the three samples, however the structure of the MTG char appeared much more damaged compared to the other ones, surely due to the brutal release of volatiles during pyrolysis. Compared to the SR and BF chars, the damage of the MTG sample can be seen through less capillaries of small diameter, presence of large cavities, collapsed intra-capillary walls and a more coarse surface (Fig. 6b, c, f, g, i, j). The MTG char presents also the peculiarity of holes on its surface, as observed in Fig. 6d, whereas this appearance was not observed for the other samples. The higher damage of char from fast pyrolysis should then enhance the transport of the gas species within the particle, leading to a faster diffusion rate compared to chars from slow pyrolysis.

In brief, higher heating rate has a positive effect on char diffusional properties, offering routes with more ease of access to the interior of the particle. The diffusion of the steam - the gasification reagent - within the particle should be then facilitated; the gasification products, $\mathrm{H}_{2}$ and $\mathrm{CO}$, should be evacuated out of the particle more rapidly, leading to lower possibilities of gasification chemical inhibition and counter-diffusion limitations. This could explain the trend of the diffusion coefficient in the model (equation (17)), which increases as the char yield decreases at higher heating rate.

Table 4

Removal of inorganics by char leaching, measured by two distinct methods (method 1: based on the ash analysis of the char samples before leaching and the washing water composition; method 2: based on the char ash analysis before and after leaching).

\begin{tabular}{|c|c|c|c|c|c|}
\hline Sample & & Ash & $\mathrm{Ca}$ & K & $\mathrm{Mg}$ \\
\hline \multirow[t]{2}{*}{ MTG- $850^{\circ} \mathrm{C}-1.8 \mathrm{~mm}$} & Method 1 & $4 \%$ & $22 \%$ & $82 \%$ & $16 \%$ \\
\hline & Method 2 & & $16 \%$ & $95 \%$ & $27 \%$ \\
\hline \multirow[t]{2}{*}{ SR-1.8 mm } & Method 1 & $3 \%$ & $39 \%$ & $100 \%$ & $26 \%$ \\
\hline & Method 2 & & $91 \%$ & $99 \%$ & $85 \%$ \\
\hline
\end{tabular}



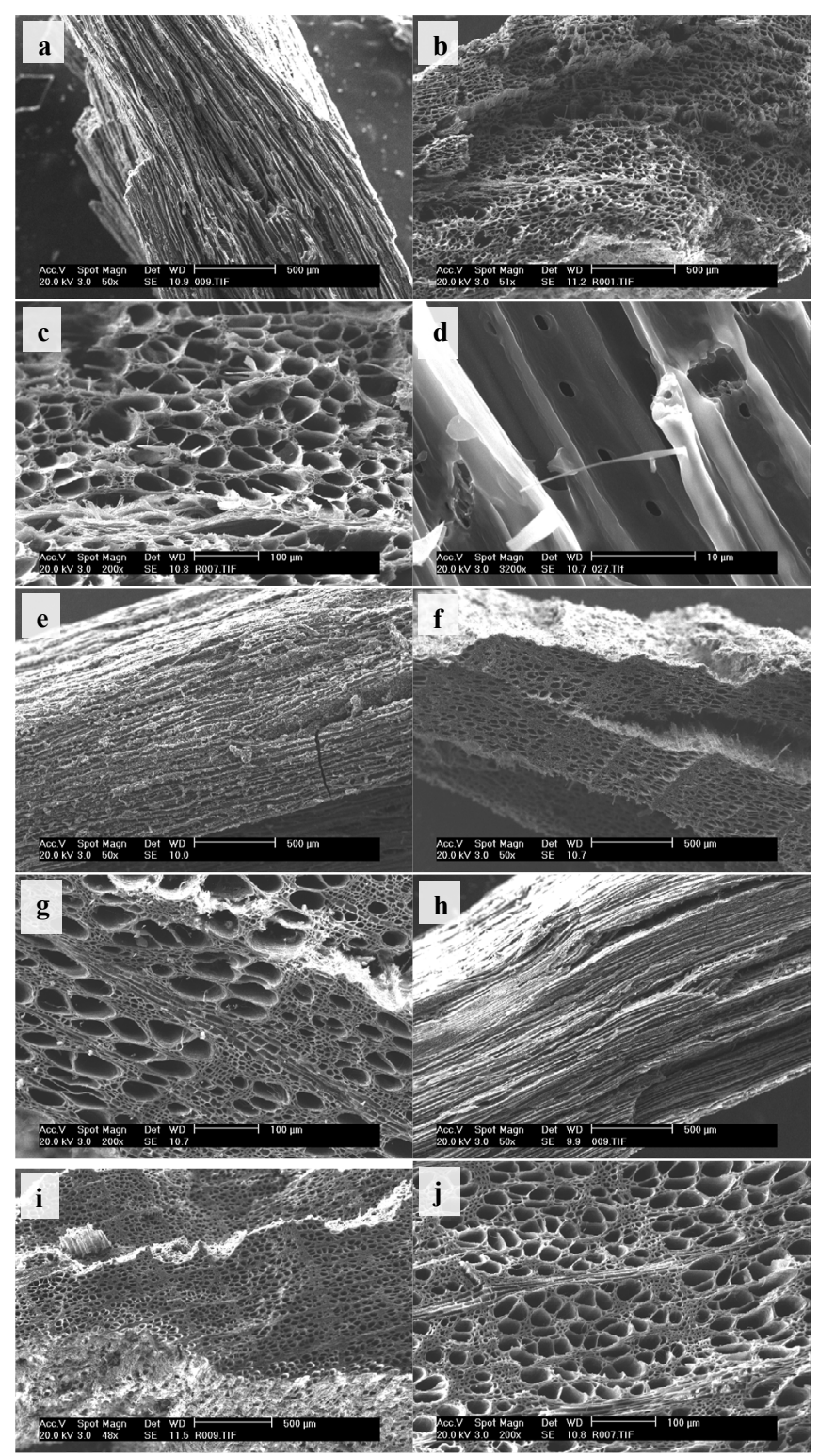

Fig. 6. SEM observations for the samples: (a), (b), (c), (d) MTG850 ${ }^{\circ} \mathrm{C}-1.8 \mathrm{~mm}$; (e), (f), (g) SR-1.8mm; (h), (i), (j) BF-1.8mm.

\subsection{Model results}

In Fig. 7, the gasification model developed in this work is confronted to experiments at different temperatures, steam concentrations, type of sample and particle size. In order to test the predictive ability of the model, the experiments selected for this comparison were not necessarily those used for the model development. The summary of the model and experimental results is provided in Table 6, which includes reactivities, Thiele modulus and efficiencies. The efficiencies and Thiele modulus were calculated according to the equations presented in section 3. It should be noted that the experimental conditions cover a wide range of efficiencies -0.07 to 1 - and Thiele modulus.

The experimental and modelling curves are similar or close in Fig. 7. The reactivity deviation between the model and the experiments rarely exceeds the experimental error bar. It can be then concluded that the modification of the gasification model by including the heating rate was performed with success. The new
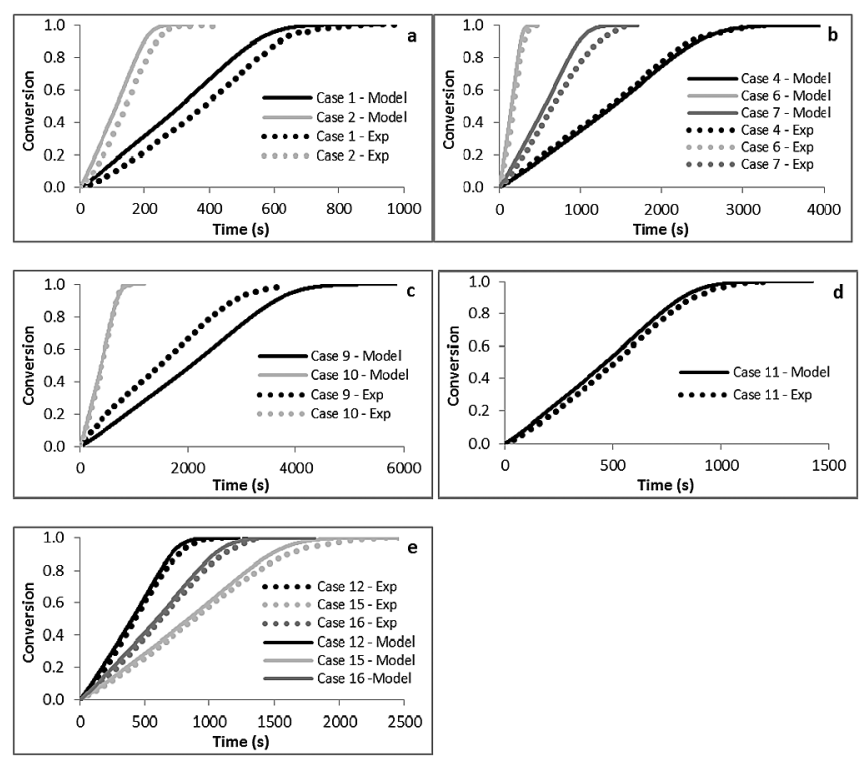

Fig. 7. Experimental and modeling conversion rates in gasification experiments (a: Case 1 and 2; b: Case 4, 6 and 7; c: Case 9 and 10; d: Case 11; e: Case 12, 15, 16).

version of the model remains simple and presents the peculiar ability to predict the gasification rate for char samples prepared at different heating rates. Considering the influence of pyrolysis conditions on char gasification rate in a simple way is an interesting feature of the model that could be further improved in future investigations. This novel modelling approach has not been yet reported in literature.

Researchers and practitioners could use this model for the prediction of gasification rate as a function of residence time, under the conditions of an atmospheric fluidized bed reactor and for char prepared under different conditions. The model does not include the external transfers, so these should be modelled aside in the case to be rate limiting.

One of the main limitations of the model is that it has been developed with only one species of wood. In the future, the correlation of char yield with heating rate should be verified with different wood species, in order to ascertain the validity of the model in a wider range of conditions.

\section{Conclusion}

This study focuses on the effect of the pyrolysis heating rate on the steam gasification of char from woodchips. Char samples exhibit a higher reactivity as the pyrolysis heating rate is higher, due to chemical and physical changes.

Thermogravimetric experiments shown faster chemical kinetics for the samples prepared under high heating rates compared to those prepared under low heating rates, because of: (i) a higher concentration of inorganics with a catalytic influence; (ii) a more reactive carbonaceous matrix. According to the morphological characterization of the samples, a char prepared under higher heating rate tends to present a more damaged structure, which may enhance gas diffusion within the solid caused by possibly a higher porosity and pore size. This would enhance the penetration of steam inside the solid, and a better evacuation of the gasification products out of the particle. In summary, the higher char reactivity by increasing the high heating rate can be explained by faster chemical kinetics and gas diffusion within the solid.

The effect of heating rate on the chemical kinetics, char physical properties and diffusion coefficient was empirically included in the 
Table 6

Experimental and modelling reactivities, Thiele modulus and efficiencies for all the experiments.

\begin{tabular}{|c|c|c|c|c|c|c|c|c|}
\hline \multirow[t]{2}{*}{ Case } & \multirow[t]{2}{*}{ Sample } & \multicolumn{2}{|c|}{ Experiments } & \multicolumn{3}{|c|}{ Reactivity (g/g/min) } & \multirow[t]{2}{*}{ Thiele modulus } & \multirow[t]{2}{*}{ Efficiency } \\
\hline & & $\mathrm{T}\left({ }^{\circ} \mathrm{C}\right)$ & $\mathrm{mol} \% \mathrm{H}_{2} \mathrm{O}$ & Exp. & Model & Dev. & & \\
\hline $\mathrm{a}$ & $\mathrm{DTR}^{\mathrm{a}}$ & 780 & 15 & $28.2 \pm 7.4$ & 24.0 & $15 \%$ & $<0.3$ & 1 \\
\hline $\mathrm{b}$ & $\mathrm{MTG} 950^{\circ} \mathrm{C}-1.8 \mathrm{~mm}^{\mathrm{a}}$ & 780 & 15 & $6.6 \pm 3.4$ & 7.4 & $12 \%$ & $<0.3$ & 1 \\
\hline c & MTG850 ${ }^{\circ} \mathrm{C}-1.8 \mathrm{~mm}^{\mathrm{a}}$ & 780 & 15 & $7.6 \pm 2.1$ & 6.7 & $12 \%$ & $<0.3$ & 1 \\
\hline d & $\mathrm{MTG} 750^{\circ} \mathrm{C}-1.8 \mathrm{~mm}^{\mathrm{a}}$ & 780 & 15 & $8.5 \pm 0.9$ & 6.1 & $28 \%$ & $<0.3$ & 1 \\
\hline e & MTG650 ${ }^{\circ} \mathrm{C}-1.8 \mathrm{~mm}^{\mathrm{a}}$ & 780 & 15 & $6.7 \pm 6.4$ & 5.2 & $22 \%$ & $<0.3$ & 1 \\
\hline f & $\mathrm{SR}-1.8 \mathrm{~mm}^{\mathrm{a}}$ & 780 & 15 & $5.3 \pm 0.2$ & 4.0 & $24 \%$ & $<0.3$ & 1 \\
\hline $\mathrm{g}$ & $\mathrm{BF}-1.8 \mathrm{~mm}^{\mathrm{a}}$ & 780 & 15 & $3.4 \pm 0.7$ & 3.5 & $2 \%$ & $<0.3$ & 1 \\
\hline $\mathrm{h}$ & MTG850 ${ }^{\circ} \mathrm{C}-1.8 \mathrm{~mm}^{\mathrm{a}, \mathrm{b}}$ & 780 & 15 & $4.4 \pm 0.2$ & N.A. & N.A. & N.A. & N.A. \\
\hline i & $\mathrm{SR}-1.8 \mathrm{~mm}^{\mathrm{a}, \mathrm{b}}$ & 780 & 15 & $2.3 \pm 0.1$ & N.A. & N.A. & N.A. & N.A. \\
\hline 1 & $\mathrm{MTG} 950^{\circ} \mathrm{C}-1.8 \mathrm{~mm}$ & 850 & 35 & $23.3 \pm 1.9$ & 24.3 & $4 \%$ & 3.7 & 0.27 \\
\hline 2 & $\mathrm{MTG} 950^{\circ} \mathrm{C}-1.8 \mathrm{~mm}$ & 950 & 35 & $60.2 \pm 12.4$ & 65.8 & $9 \%$ & 15.0 & 0.07 \\
\hline 3 & $\mathrm{MTG} 850^{\circ} \mathrm{C}-0.6 \mathrm{~mm}$ & 850 & 35 & $41.3 \pm 3.4$ & 55.3 & $34 \%$ & 1.6 & 0.58 \\
\hline 4 & $\mathrm{MTG} 850^{\circ} \mathrm{C}-1.2 \mathrm{~mm}$ & 770 & 20 & $5.4 \pm 0.5$ & 5.3 & $1 \%$ & 0.8 & 0.83 \\
\hline 5 & $\mathrm{MTG} 850^{\circ} \mathrm{C}-1.2 \mathrm{~mm}$ & 870 & 45 & $47.2 \pm 33.2$ & 49.9 & $6 \%$ & 3.5 & 0.29 \\
\hline 6 & $\mathrm{MTG} 850^{\circ} \mathrm{C}-1.8 \mathrm{~mm}$ & 850 & 35 & $22.3 \pm 1.4$ & 22.0 & $1 \%$ & 3.7 & 0.27 \\
\hline 7 & $\mathrm{MTG} 850^{\circ} \mathrm{C}-2.4 \mathrm{~mm}$ & 930 & 10 & $11.7 \pm 4.8$ & 13.4 & $14 \%$ & 18.3 & 0.05 \\
\hline 8 & MTG850 ${ }^{\circ} \mathrm{C}-3.0 \mathrm{~mm}$ & 850 & 35 & $16.5 \pm 0.8$ & 13.9 & $16 \%$ & 5.5 & 0.18 \\
\hline 9 & $\mathrm{MTG} 750^{\circ} \mathrm{C}-1.8 \mathrm{~mm}$ & 750 & 35 & $4.4 \pm 1.3$ & 3.6 & $19 \%$ & 0.8 & 0.85 \\
\hline 10 & $\mathrm{MTG} 750^{\circ} \mathrm{C}-1.8 \mathrm{~mm}$ & 850 & 35 & $19.9 \pm 1.3$ & 18.9 & $5 \%$ & 3.9 & 0.25 \\
\hline 11 & MTG $650^{\circ} \mathrm{C}-1.8 \mathrm{~mm}$ & 850 & 35 & $16.1 \pm 4.6$ & 15.5 & $4 \%$ & 4.1 & 0.24 \\
\hline 12 & SR-0.6 mm & 850 & 35 & $18.6 \pm 1.4$ & 20.6 & $11 \%$ & 2.3 & 0.42 \\
\hline 13 & $\mathrm{SR}-1.2 \mathrm{~mm}$ & 820 & 40 & $10.4 \pm 1.5$ & 12.2 & $18 \%$ & 1.9 & 0.51 \\
\hline 14 & $\mathrm{SR}-1.8 \mathrm{~mm}$ & 850 & 35 & $12.1 \pm 0.7$ & 13.1 & $9 \%$ & 3.7 & 0.27 \\
\hline 15 & SR-3.0 mm & 850 & 35 & $8.5 \pm 0.8$ & 8.2 & $4 \%$ & 6.0 & 0.17 \\
\hline 16 & SR-3.0 mm & 930 & 20 & $12.3 \pm 5.7$ & 11.6 & $6 \%$ & 20.6 & 0.05 \\
\hline 17 & $\mathrm{BF}-1.8 \mathrm{~mm}$ & 810 & 15 & $2.9 \pm 0.3$ & 3.0 & $2 \%$ & 2.7 & 0.37 \\
\hline 18 & $\mathrm{BF}-1.8 \mathrm{~mm}$ & 850 & 35 & $10.0 \pm 8.6$ & 9.9 & $1 \%$ & 4.4 & 0.23 \\
\hline 19 & $\mathrm{BF}-1.8 \mathrm{~mm}$ & 930 & 30 & $22.0 \pm 1.0$ & 19.0 & $14 \%$ & 14.0 & 0.07 \\
\hline
\end{tabular}

${ }^{\text {a }}$ ground sample.

b leached sample.

gasification model. The new version of the model gives accurate predictions and allows describing gasification of char samples prepared under a heating rate range as wide as $0.05-1000 \mathrm{~K} \mathrm{~s}^{-1}$. The model could be used to predict gasification rate in fluidized bed reactor in the context of Gaya project and for further applications where the char will be prepared at different heating rates.

\section{Funding}

This work was supported by the ADEME (Grant number 0901C0124).

\section{Acknowledgments}

The authors would like to acknowledge all the collaborators from GAYA project, in particular the members from the CEA, CIRAD, LRGP, LGC and GDF SUEZ. We also thank the invaluable support of the technical staff at the 'Ecole des Mines d'Albi', especially Mr. Bernard AUDUC, Mr. Denis MARTY and Mrs. Celine Boachon, as the PhD student Pierre-Marie Nigay for his experimental help.

\section{References}

[1] Septien S, Escudero-Sanz FJ, Salvador S, Valin S. Steam gasification of char from wood chips fast pyrolysis: development of a semi-empirical model for a fluidized bed reactor application. Biomass Bioenergy 2015;77:64-74.

[2] Groeneveld MJ, van Swaaij WPM. Gasification of char particles with $\mathrm{CO} 2$ and H2O. Chem Eng Sci 1980;35(1-2):307-13.

[3] Brem G, Brouwers JJH. Analytical solutions for non-linear conversion of a porous solid particle in a gas - II. Non-isothermal conversion and numerical verification. Chem Eng Sci 1990;45(7):1915-24.

[4] Brem G, Brouwers JJH. Analytical solutions for non-linear conversion of a porous solid particle in a gas - I. Isothermal conversion. Chem Eng Sci 1990:45(7):1905-13.

[5] Gómez-Barea A, Ollero P. An approximate method for solving gas-solid noncatalytic reactions. Chem Eng Sci 2006;61(11):3725-35.
[6] Mermoud F, Golfier F, Salvador S, Van de Steene L, Dirion JL. Experimental and numerical study of steam gasification of a single charcoal particle. Combust Flame 2006:145(1-2):59-79.

[7] Teixeira G, Van de steene L, Ponthieux A, Salvador S. Prediction of the gasification kinetics of a single wood char particle from a limited set of parameters. Fuel 2014;123:194-204.

[8] Dyrness A, Glicksman LR, Yule T. Heat transfer in the splash zone of a bubbling fluidized bed. Int J Heat Mass Transf 1992;35(4):847-60.

[9] Oka SN. Fluidized bed combustion - chapter 3. Heat and mass transfer in fluidized beds. In: Anthony EJ, editor. Fluid. Bed combust. New York: Marcel Dekker; 2004. p. 147-210.

[10] Agarwal PK. Transport phenomenain multi-particles systems. IV, Heat transfer to a large freely moving particle in gas fluidized bed of smaller particles. Chem Eng Sci 1991;46(4):1115-27.

[11] Milosavljevic I, Oja V, Suuberg EM. Thermal effects in cellulose pyrolysis: relationship to char formation processes. Ind Eng Chem Res 1996;35:653-62.

[12] Fushimi C, Araki K, Yamaguchi Y, Tsutsumi A. Effect of heating rate on steam gasification of biomass. 1. Reactivity of char. Ind Eng Chem Res 2003;42: 3922-8.

[13] Roberts DG, Harris DJ, Wall TF. On the effects of high pressure and heating rate during coal pyrolysis on char gasification reactivity. Energy \& Fuels 2003;17: 887-95.

[14] Cetin E, Gupta R, Moghtaderi B. Effect of pyrolysis pressure and heating rate on radiata pine char structure and apparent gasification reactivity. Fuel 2005;84:1328-34.

[15] Cetin E, Moghtaderi B, Gupta R, Wall TF. Influence of pyrolysis conditions on the structure and gasification reactivity of biomass chars. Fuel 2004;83: 2139-50.

[16] Biagini E, Simone M, Tognotti L. Characterization of high heating rate chars of biomass fuels. Proc Combust Inst 2009:32:2043-50.

[17] Okumura Y, Hanaoka T, Sakanishi K. Effect of pyrolysis conditions on gasification reactivity of woody biomass-derived char. Proc Combust Inst 2009;32: 2013-20.

[18] Guerrero M, Ruiz MP, Alzueta MU, Bilbao R, Millera A. Pyrolysis of eucalyptus at different heating rates: studies of char characterization and oxidative reactivity. J Anal Appl Pyrolysis 2005;74:307-14.

[19] Su S, Song Y, Wang Y, Li T, Hu S, Xiang J, et al. Effects of CO2 and heating rate on the characteristics of chars prepared in $\mathrm{CO} 2$ and N2 atmospheres. Fuel $2015 ; 142: 243-9$.

[20] Mermoud F, Salvador S, de Steene L Van, Golfier F. Influence of the pyrolysis heating rate on the steam gasification rate of large wood char particles. Fuel 2006;85:1473-82.

[21] Zanzi R, Sjöström K, Björnbom E. Rapid high-temperature pyrolysis of biomass 
in a free-fall reactor. Fuel 1996;75:545-50.

[22] Kristiansen A. Understanding coal gasification. London: IEA Coal Research; 1996.

[23] Zeng K, Minh DP, Gauthier D, Weiss-Hortala E, Nzihou A, Flamant G. The effect of temperature and heating rate on char properties obtained from solar pyrolysis of beech wood. Bioresour Technol 2015;182:114-9.

[24] Lu L, Kong C, Sahajwalla V Harris D. Char structural ordering during pyrolysis and combustion and its influence on char reactivity. Fuel 2002;81:1215-25.

[25] Noubli H, Valin S, Spindler B, Hemati M. Development of a modelling too representing biomass gasification step in a dual fluidized bed. Can J Chem Eng 2015;93(2):340-7.

[26] Guizani C, Escudero Sanz FJ, Salvador S. Effects of CO2 on biomass fast pyrolysis: reaction rate, gas yields and char reactive properties. Fuel 2014;116: 310-20.

[27] Tagutchou J-P. Gazéification du charbon de plaquettes forestières: particule isolée et lit fixe continu. PhD thesis. University of Perpignan; 2008.

[28] Van de steene L, Tagutchou JP, Escudero Sanz FJ, Salvador S. Gasification of woodchip particles: experimental and numerical study of char-H2O,
char-CO2, and char-O2 reactions. Chem Eng Sci 2011;66(20):4499-509.

[29] Septien S, Valin S, Dupont C, Peyrot M, Salvador S. Effect of particle size and temperature on woody biomass fast pyrolysis at high temperature $\left(1000-1400^{\circ} \mathrm{C}\right)$. Fuel 2012;97:202-10.

[30] Chen L, Dupont C, Salvador S, Grateau M, Boissonnet G, Schweich D. Experimental study on fast pyrolysis of free-falling millimetric biomass particles between $800^{\circ} \mathrm{C}$ and $1000^{\circ} \mathrm{C}$. Fuel 2013;106:61-6.

[31] Zhang Y, Ashizawa M, Kajitani S, Miura K. Proposal of a semi-empirical kinetic model to reconcile with gasification reactivity profiles of biomass chars. Fuel 2008;87(4-5):475-81.

[32] Dupont C, Nocquet T, Da Costa JA, Verne-Tournon C. Kinetic modelling of steam gasification of various woody biomass chars: influence of inorganic elements. Bioresour Technol 2011;102:9743-8.

[33] Jensen PA, Sander B, Dam-Johansen K. Removal of $\mathrm{K}$ and $\mathrm{Cl}$ by leaching of straw char. Biomass Bioenergy 2001;20:447-57.

[34] Di Blasi C. Combustion and gasification rates of lignocellulosic chars. Prog Energy Combust Sci 2009;35(2):121-40. 